\title{
The Physico-Mechanical Properties of Unsaturated Polyester Resin Filled with Huracrepitan Pod for Wall Tiles Application
}

\author{
Ibeneme Uche ${ }^{1}$, Ejiogu Ibe Kevin ${ }^{2}$, Umar Muhammad Hamis ${ }^{1}$, Egwu Chinwe Euphemia ${ }^{3}$, \\ Aiyejegbara Mosunmade Olukemi ${ }^{1}$, Ugbaja Michael Ifeayichukwu ${ }^{1}$ \\ ${ }^{1}$ Department of Polymer Technology, Nigerian Institute of Leather and Science Technology, Zaria, Nigeria \\ ${ }^{2}$ Directorate of Research and Development, Nigerian Institute of Leather and Science Technology, Zaria, Nigeria \\ ${ }^{3}$ Department of Science laboratory Technology, Nigerian Institute of Leather and Science Technology, Zaria, Nigeria
}

Email address:

ucheibeneme2016@gmail.com (I. Uche)

${ }^{*}$ Corresponding author

\section{To cite this article:}

Ibeneme Uche, Ejiogu Ibe Kevin, Umar Muhammad Hamis, Egwu Chinwe Euphemia, Aiyejegbara Mosunmade Olukemi, Ugbaja Michael Ifeayichukw. The Physico-Mechanical Properties of Unsaturated Polyester Resin Filled with Huracrepitan Pod for Wall Tiles Application. American Journal of Chemical and Biochemical Engineering. Vol. 2, No. 1, 2018, pp. 16-21. doi: 10.11648/j.ajcbe.20180201.13

Received: June 26, 2018; Accepted: August 16, 2018; Published: September 12, 2018

\begin{abstract}
Huracrepitan pod was the fibre material used for this research and unsaturated polyester resin was used as the matrix. The huracrepitan pod was crushed with the aid of the Thomas-Willey laboratory mill machine, model 4 and was sieved using a standard sieve of $250 \mu \mathrm{m}$. The crushed huracrepitan pod was then soaked in a standard solution of $20 \%$ Sodium Hydroxide for 24 hours and washed with distilled water. It was later dried in the oven for an hour for final removal of moisture. $\mathrm{I} 00 \mathrm{~g}$ of unsaturated polyester resin was reinforced with huracrepitan pod particles of filler loadings of $0 \mathrm{~g}, 10 \mathrm{~g}, 20 \mathrm{~g}, 30 \mathrm{~g}$, and $40 \mathrm{~g}$., while $90 \mathrm{~g}, 80 \mathrm{~g}, 70 \mathrm{~g}$ and $60 \mathrm{~g}$ of unsaturated polyester resin were reinforced with $20 \mathrm{~g}, 30 \mathrm{~g}$ and $40 \mathrm{~g}$ huracrepitan pod.The composites obtained were cut into dumbbell shapes and characterized to assess their performance. The hardness was enhanced to the maximum of 99.00 Shore A at $40 \%$ filler loading the percentage water absorption was found to be $0.3 \mathrm{~g}$. Pure unsaturated polyester resin recorded hardness of 94.67 Shore A, and water absorption of $0.30 \mathrm{~g}$ and the percentage elongation optimum was found to be $15 \%$ at $40 \%$ filler loading and $2.5 \%$ at $0 \%$ filler loading. The results indicated that the use of huracrepitan pod particles as reinforcement can enhance the properties of polyester composites. It was observed that the samples with the highest filler loading absorbed more impact energy and also increased the elongation percentage. The application of Huracrepitan pod as filler in this work improved the mechanical properties of the thermosetting polymer.
\end{abstract}

Keywords: Huracrepitan Pod, Unsaturated Polyester Resin, Composite, Filler Loading, Fibers

\section{Introduction}

Originating from early agricultural societies and being almost forgotten for centuries, a true revival started of using lightweight composite structures for many technical solutions during the second half of the 20th century. After being solely used for their electromagnetic properties (insulators and radar-domes), using composites to improve the structural performance of spacecraft and military aircraft became popular in the last two decades of the previous century. First at any costs, with the development of improved materials with increasing costs, nowadays cost reduction during manufacturing and operation are the main technology drivers. The latest development is the use of composites to protect man against fire and impact and a tendency to a more environmentally friendly design, leading to the reintroduction of natural fibres in the composite technology [1].

Advanced composite has become the accepted term for materials manufactured from long or continuous reinforcing fibres, usually in excess of $50 \%$ by volume, embedded in a compatible matrix. One of the first systems developed was glass reinforced polyester (GRP). Today, a large range of fibres and matrix materials are available and so the more general term fibre reinforced plastics (FRP) is frequently used. Advanced composites offer low density, corrosion 
resistance, and good insulation properties, in addition to high strength and stiffness. They have become established in a diverse range of industries, from consumer products to space research [7].

The Huracrepitan pods are considered as a waste product in the environment. The huracrepitan pod may also be used as food for ruminant, and vegetable oil source. The use of natural fibers in polyester resins composites serves to improve the mechanical properties of the polymer such as Tensile strength, hardness, and impact strength. Fibers sourced cellulosic materials are considered to be of relatively higher strength, lower density, cheaper, relatively abundant and renewable. The present study is channeled towards producing a composite using an unsaturated polyester resin (as a matrix) and huracrepitan pod particle (as reinforcement) and to investigate the effect of huracrepitan pod particles on the mechanical and physical properties of the composite [4]. In its introduced range, Huracrepitan occurs in rainforest edges and gaps. Another name for this tree is monkey pistol. Huracrepitan is widely occurring self-regenerating ornamental plant in the tropical and often and planted in towns and villages as a cover tree. The tree has beautiful seed pods that are made out of wood when the seed pods are perfectly ripe the individual segment which are separated seeds, burst apart making a sharp cracking sound like pistol been fired. Fishermen have been said to use the milky, caustic sap from this tree to poison fish. The Caribs made arrow poison from its sap. The wood is used for furniture under the name "hura". Before more modern forms of pens were invented, the trees' unripe seed capsules were sawn in half to make decorative pen sandboxes (also called pounce pots), hence the name 'sandbox tree' [3].

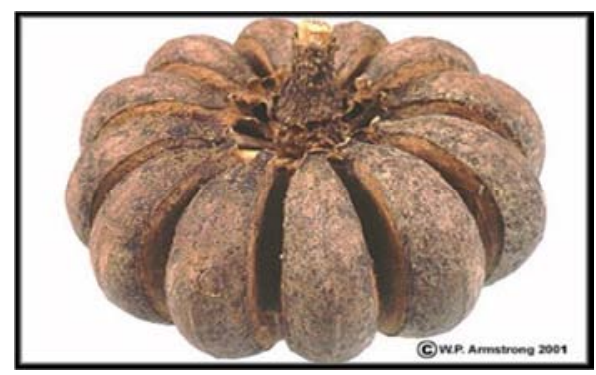

Figure 1. Hura Creptan Pod

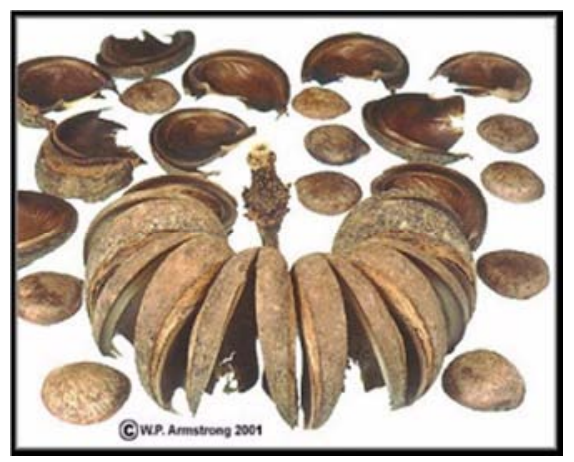

Figure 2. Huracreptan Seed Shell

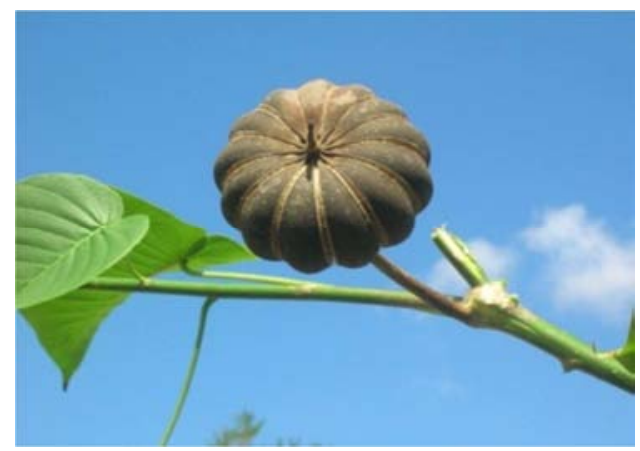

Figure 3. Hura Creptan Pod Leaf

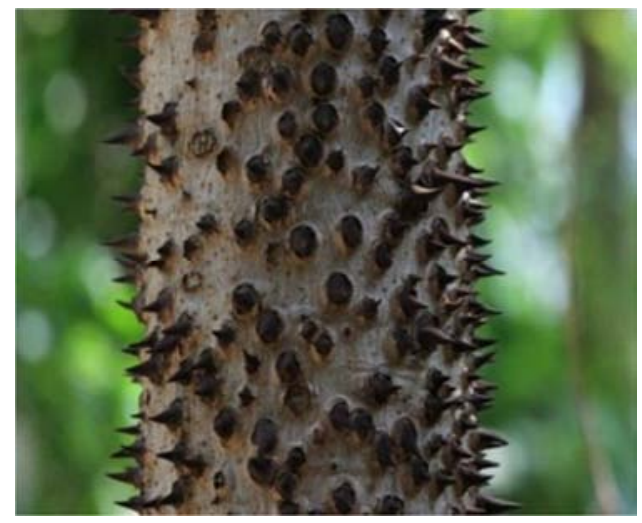

Figure 4. Hura Crepitan Pod and Plant Stem

Composites are combinations of two materials in which one of the materials in the form of fibers, sheets, or particles called the reinforcing phase, is embedded in the other material called the matrix phase. Composite materials are those made from two or more materials with significantly different physical or mechanical properties, that when combined produce a material with characteristics different from the individual components. The individual remains separate and distinct within the finished structure. The new materials may be prepared for many reasons; materials which are stronger, lighter or less expensive when compared to traditional materials. Examples of composites; Engineering composites (building material such as cement, concrete), Reinforced plastics (fiber-reinforced polymer), Metal composites, Ceramic composites (composite ceramic and metal matrix) and Polymer composite [5]. Polymer composite materials have generated wide interest in various engineering fields, particularly in aerospace applications. Research is underway worldwide to develop newer composites with varied combinations of fibres and fillers so as to make them useful under different operational conditions [2]. The advantage of composite materials over conventional materials stem largely from their higher specific strength, stiffness, The high strength to weight ratio and fatigue characteristics which enables structural designs to be more versatile. They are not only used because of their structural properties but also due to their electrical, thermal, tribological applications. Composite materials are nothing new. Early builders put the principle to good use by reinforcing mud with twigs, with some of these wattle and 
daub structures still standing today. Wood is a naturally occurring composite, consisting of strong, reinforcing cellulose fibres in a weak lignin resin matrix. However, in recent years there has been much research effort towards understanding the properties of composites, and this has led to them gaining acceptance among engineering designers [10].

Composites have high specific strength and modulus as well as high fatigue strength and fatigue damage tolerance. They have good damping characteristics and low coefficient of thermal expansion [8]. They are less noisy while in operation and provide lower vibration transmission than metals and they are more versatile than metals and can be tailored to meet performance needs and complex design requirements [6]. Polyester resins are the most widely used resin systems, particularly in the marine industry. By far the majority of dinghies, yachts, and workboats built in composites make use of this resin system.

Polyester resins such as these are of the 'unsaturated' type. The unsaturated polyester resin is a thermoset, capable of being cured from a liquid to solid state when subjected to the right conditions. It is usual to refer to unsaturated polyester resins as 'polyester resins', or simply as 'polyesters'. There is a whole range of polyesters made from different acids, glycols and monomers, all having varying properties [9]. Swaine and Beer (11) observed that the seed of the huracrepitan pods explodes and dieperse up to 14 meters away. The huracrepitan pods were to Africa as a shade tree. Wermer and Alters (12) studied the behavior of the kernel seed of the huracrepitan pods in a reservoir. They observed that after much pressure has been exerted and dripping of the oil into the reservoir has finally stopped, the weight of the cake left, and that of the oil collected in the reservoir were recorded.

Percentage of oil yield $=$ Weight of oil collected $/$ Weight of oil crushed oil x 100

Otoikhian et al (13)1 studied the mechanical extraction and fuel properties evaluation of huracrepitan seed oli. They collected huracrepitan seeds from huracrepitan tree and extracted oil by mechanical screw press at a constant pressure of $25 \mathrm{~N} / \mathrm{m}^{2}$. Bodger (14) investigated the extraction, refining and composition of oil from winged bean. He observed that good quality oil will deteriorate quickly, if it contains oil seed residues particles of seed debris should be removed from the oil as soon as possible after extraction of the oil. Alabi et al (15) carried out analysis of fatty acid composition of thevetia perviana and huracrepitan seeds oil. They observed that the palmitic acid contet of the huracrepitan seeds oli was $8.84 \%$ which is lower than $14.39 \%$ reported for jatropha curcas seed oil and $26.9 \mathrm{~b} \%$ was reported for for thevita peruviana.

\section{Experimental Methods}

\section{Materials}

Huracrepitan pod was obtained from Samaru Village, Zaria. The Unsaturated Polyester resin, methyl-ethyl-ketone peroxide, and cobalt naphthenate were obtained from a photographic shop, Sabon Gari-Zaria, Kaduna State. The collected pod was crushed with a crusher (Thomas Wiley Laboratory Mill, Model 4) and sieved with a Standard test Sieve of $250 \mu \mathrm{m}$ and was treated with $20 \%$ sodium hydroxide $(\mathrm{NaOH})$ and dried in an oven. The unsaturated polyester resin with various filler loading was mixed together, Methyl ethyl ketone peroxide (MEKP) and cobalt naphthenate were used to speed up the rate of the polymerization reaction.

\section{Method}

\subsection{Treatment of the Fibre}

The fibre was soaked in a standard solution of $20 \%$ sodium hydroxide $(\mathrm{NaOH})$ for 24 hours in order to remove the impurities of the fibre such as lignin, waxes, paraffin, and starch, it was then removed and washed thoroughly with acetic acid followed by a thorough wash with distilled water and dried in an oven to remove the moisture contents of the fibre.

Crushing of the Hura Crepitan Pod

The huracrepitan pod was crushed using a crusher (Thomas Wiley Laboratory Mill, Model 4) and sieved into the required particle size of $250 \mu \mathrm{m}$

\subsection{Casting of the Composite}

Composites were prepared using variable quantities of huracrepitan pod. The mold for every casting was properly scraped, cleaned and well lubricated with mirror glaze and the various ratios of resin/fiber were measured using a weighing balance. The castings of the various samples were done using a metal mould. Methyl-ethyl-ketone-peroxide catalyst and cobalt naphthenate were used to speed the rate of the polymerization reaction. Unsaturated polyester resin composites of desired thickness were prepared and the dimensions of the samples were cut in accordance to mechanical test to be carried out.

Table 1. Formulation Table for Production of the Composite.

\begin{tabular}{lllll}
\hline Sample & The composition of Polyester $(\mathbf{g})$ & Filler Loading $(\mathbf{g})$ & Catalyst(\%) & Accelerator (\%) \\
\hline Sample A & 100 & 0 & 0.05 & 1 \\
Sample B & 90 & 10 & 0.05 & 1 \\
Sample C & 80 & 20 & 0.05 & 1 \\
Sample D & 70 & 30 & 0.05 & 1 \\
Sample E & 60 & 40 & 0.05 & 1 \\
\hline
\end{tabular}




\subsection{Tests Carried Out on the Composite}

\subsubsection{Tensile Test (ASTM D3039)}

Hounsfield (Monsanto) tensometer (Universal Testing Machine) (model No. S/N8889) was used to determine the percentage of elongation in the length of the materials. The specimen geometry was in a dumb-bell shape and the dimensions were ascertained using the vernier calipers. The uni-axial load was applied to each end of the respective samples until it snaps (ruptures).

\subsubsection{Impact Strength Test (ASTM D 7136)}

The Charpy impact testing machine was used. Samples of dimensions, with a notch of $2 \mathrm{~mm}$ at $45^{\circ}$ radii was placed in a Charpy V-notch across the parallel jaw in the machine. The heavy pendulum was then released from a known height to strike the samples on its downward swing which fractured the samples. The energy absorbed was noted and recorded.

\subsubsection{Hardness Test (ASTM D 4762)}

Hardness test was conducted using the Durometer Tester of Indentech, UK (Model 8187.5 LKV) the dimension of the prepared test samples was measured (in $\mathrm{mm}$ ) and surface smoothness was maintained. An average was taken after three times of test by summing the test values by the total number of test taken.

\subsubsection{Water Absorption Test (D 5229)}

Samples were weighed and kept in a distilled water for 48 hours and were then removed and re-weighed again to find the percentage of water absorbed in each of the samples.

$$
\begin{array}{r}
\text { Percentage of water absorbed } \\
\text { (\%) } \frac{\text { weight of wet sample-weight of dry sample }}{\text { weight of dry sample }} \times 100
\end{array}
$$

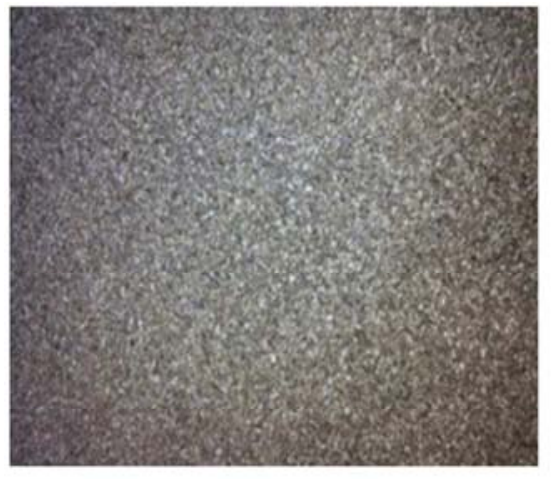

Plate A: Crushed huracrepitan pod $(1 \mathrm{~mm})$

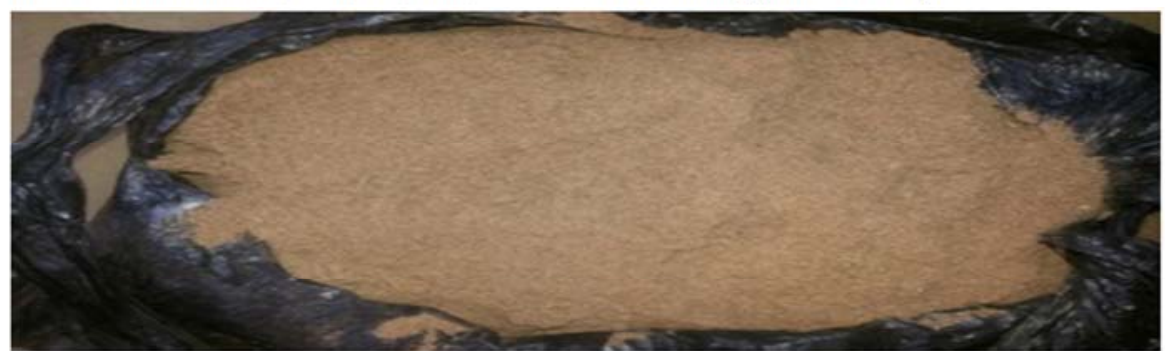

Plate C: Sieved huracrepitan pod $(250 \mu \mathrm{m})$

Figure 5. Pictorial Representation of Crushed and Sieved Huracrepitan Pod.

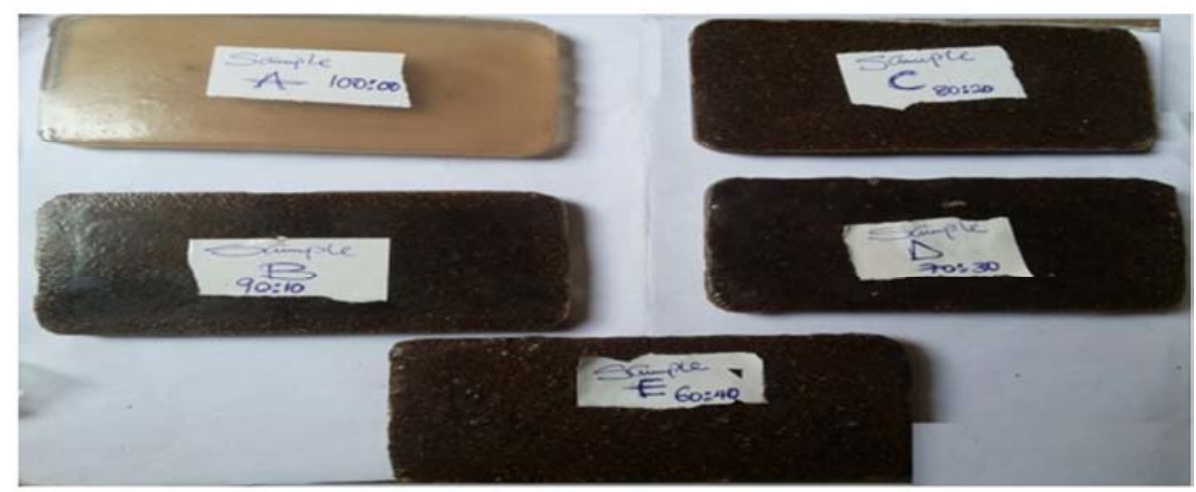

Plate D: Casted Composite materials

Figure 6. Sample of Unsaturated Polyester Resin Filled with Huracrepitan Pod. 


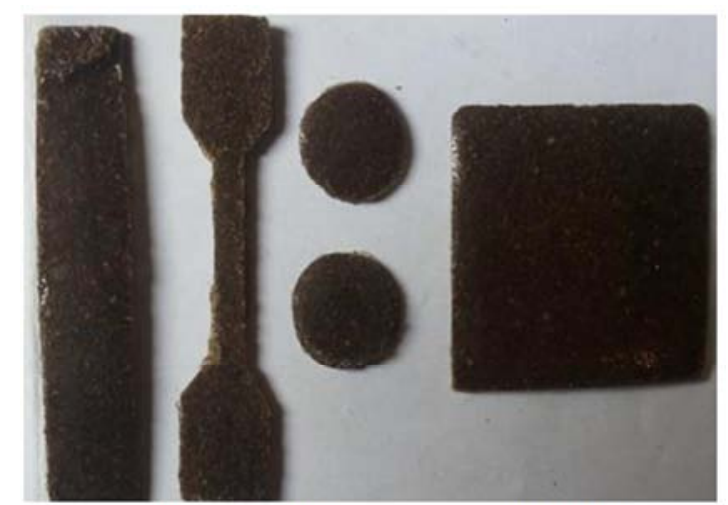

Plate E: Prepared samples of composite for testing

Figure 7. Samples Cut out from Composite for Physico- Mechanical Test.

\section{Results and Discussions}

\subsection{Hardness Test Result}

The hardness result test is shown in Figure 8. Hardness is the relative resistance of the surface of the samples to indentation by an indentor of specified dimension under a specified load. It is generally known that fillers increase the hardness of polymer materials. In the case of the unsaturated polyester resin, as the filler loading increased there was a corresponding increase in the hardness of the composite from $0-40 \mathrm{~g}$. The hardness increased from 94.67 Shore A to 99.00 Shore A. This result is expected because as more filler gets into the unsaturated polyester resin matrix, it helped to reduce the brittleness of the polymer thereby increasing the hardness due to strong matrix filler interaction.

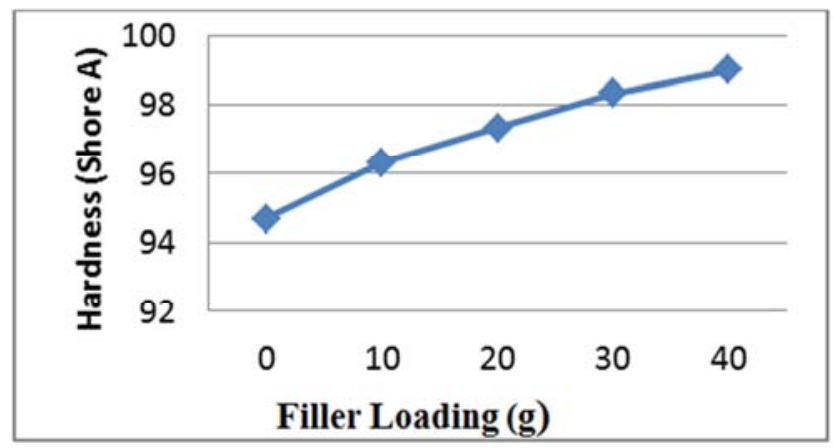

Figure 8. A Graph of Hardness against Filler Loading.

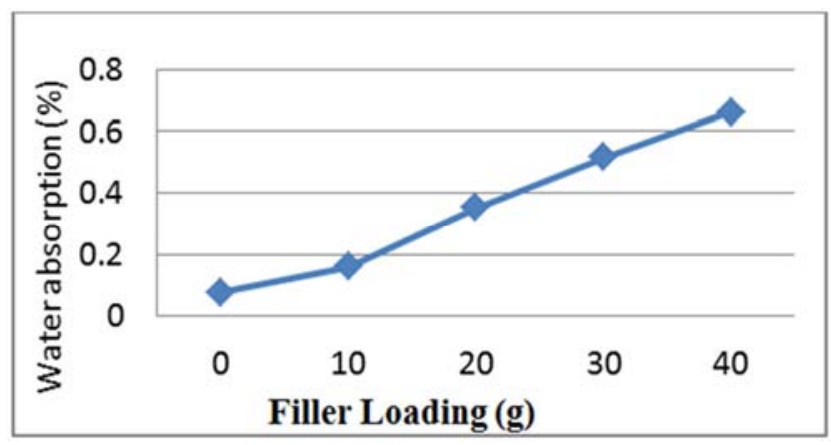

Figure 9. A Graph of Water Absorption against Filler

\subsection{Water Absorption Test}

The water absorption test is shown in Figure 9. The result showed that the higher the filler loading the higher the water absorption of the composite. This is observed because the huracrepitan pod is an organic filler they are hydrophilic in nature (water-loving), thus higher filler content meant higher water absorption in the composite. However compared with the conventional floor tiles the composite still had very low water resistance, thus this makes unsaturated polyester resin/huracrepitan pod composite good substituents for wall tiles.

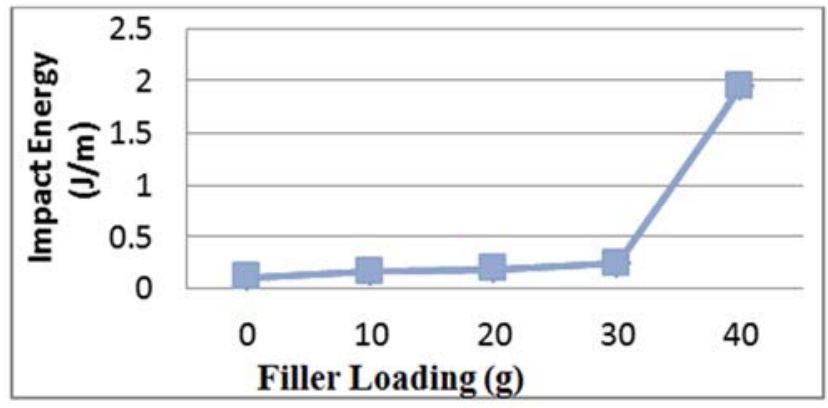

Figure 10. Graph of impact strength against filler loading.

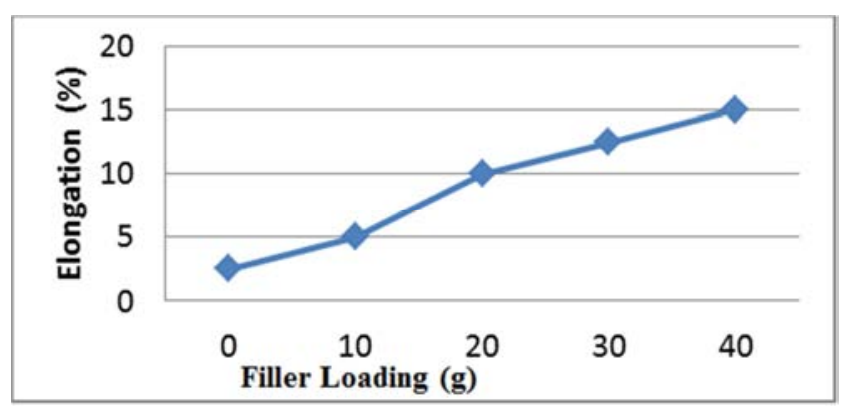

Figure 11. Graph of\% elongation against filler loadings

\subsection{Impact Test Result}

For the impact strength, as shown in Figure 10, the sample with the highest filler loading has the highest impact strength. The impact strength increased as the filler loading increased.

\subsection{Elongation at Break Test}

From Figure 11 shown above, as the sample of filler loading in the composite increased the percentage elongation at break of the polyester resin/huracrepitan pod composite also increased.

\section{Conclusion and Recommendation}

\subsection{Conclusion}

The results of this investigation showed that Huracreptan pod particles can be used as reinforcement in composites production. The mechanical and the physical properties of the polyester resin/huracrepitan pod composite were found to be influenced by the filler loadings and the following 
conclusions may be drawn from the findings of the investigation showed the Hardness of the composites increased with increase in filler loading of particle size $250 \mu \mathrm{m}$, from 94.67 Shore A to 99.00 Shore A. The elongation of the composite increased with increase in filler loading, similarly impact strength improved with an increase in filler loadings and even though water absorption increased in the polyester resin/huracrepitan pod composite as the filler loading increased the water absorption was still low enough such that the composite can still be utilized as a wall tile.

\subsection{Recommendations}

The following recommendations are made to further improve on this work in future one should ensure that varying particle sizes ranging for $250 \mu \mathrm{m}, 72 \mu \mathrm{m}, 100 \mu \mathrm{m}$, $150 \mu \mathrm{m}$ should also be used to achieve the best particle size that will give an optimal result for the composite.

Secondly, varying concentration of alkaline treatment should be carried out on the filler to see the effect of this treatment on the properties of the composite, to better explain the matrix -filler interaction.

Thirdly, the study should be done on the huracrepitan plant to see the commercial viability of utilizing the pod on a commercial scale as filler for composites and polymer composite technology and finally further work should be done on the huracrepitan pod to ascertain the possibility of using it for ceiling tiles, sandpapers, and natural pozzolanic materials.

\section{Conflict of Interest}

The authors declared no conflict of interest in this work.

\section{References}

[1] The Open University (UK), (2000). T838 Design and Manufacture with Polymers: Introduction to Polymers, page 9. Milton Keynes: The Open University.

[2] Chandramohan D. and K Manninmathu (2011a): drilling of natural fiber particles reinforced polymer composites materials, International Journal of advanced engineering research and studies. Vol. 1. Tissue 1 October-December, 2011, pg 134-145.
[3] Jones. David E (2007). Poison arrows: North American Indian huntingandwarefare. University of Texas Press. ISBN 978-0292-71428-1.

[4] Kabirat (2016) preparation and characterization of polypropylene composite filled with huracrepitan pod particles.

[5] Waterman, Pamela J. (2007): "the life of composite material" Desktop Engineering Magazine.

[6] Chandramohan D., Marimuthu K., A research review on natural fibers, Proceedings of the International Journal of Current Research, (2011b), 3(11), p. 331-337.

[7] Pilato, L, Michno, Michael, J(1994) Advanced Composite materials, Springer-Verlag. Newyork, ISBN 978-3-54057563-4.

[8] Campbell, F, (2010). Thermoset Composite Fabrication processes, in: Structural composite materials. S, I, ASM International pp 119-182.www.asm international.org.

[9] Francesca, S, Simonia, B, Maria-Bentrica(2008) Po(Lactic acid) Properties as a consequence of poly(butylene) adipateco-terephthalate) blending and acetyltributyl citrate plastication. Journal of applied Polymer Science.

[10] Dwayne, A,(2003) Composites and advanced materials NASA, $U, S$, Centennialof flight commission

[11] Swaine M. D, Beer T, (1977) Expolosive Seed dispersal in Huracrepitans New Phytologist, 78(3), 695-708.

[12] Wermer H. J, A and Alters F. W. K, (1989) Small Scale Processing of Oil Fruits and Oil Seeds. Eshborn, Germany.

[13] Otoikhian, S. K Aluyor E, O and Audu T. O. K (2016) Mechanical Extraction and Fuel Properties Evaluation of Huracrepitans seed oil. Indian Journal of Chemical Technology. Volume 11(6).

[14] Bodger D.(1982) Investigation of the Extraction, Refining and Composition of Oil From Winged Bean (PSO, Phocarpus Tetragonolobus) Journal of American Oil Chemical Society, 59 (12) $523-30$

[15] Alabi K. A., Lajide, L., Owolabi, B. J., (2013). Analysis of Fatty Acid Composition of Thevetia Peruviana and Huracrepitans Seed Oil Using GD-F. D Fountain. Journal of Natural and Applied Science. 2(2) 327. 